Portland State University

PDXScholar

\title{
The Kin Composition of Social Groups: Trading Group Size for Degree of Altruism
}

\author{
Leticia Avilés \\ University of British Columbia \\ Jeffrey Alan Fletcher \\ Portland State University, jeff@pdx.edu \\ Asher D. Cutter \\ University of Arizona
}

Follow this and additional works at: https://pdxscholar.library.pdx.edu/sysc_fac

Part of the Evolution Commons

Let us know how access to this document benefits you.

\section{Citation Details}

The Kin Composition of Social Groups: Trading Group Size for Degree of Altruism. Leticia Avilés, Jeffrey A. Fletcher, and Asher D. Cutter The American Naturalist, Vol. 164, No. 2 (August 2004), pp. 132-144. Published by: The University of Chicago Press for The American Society of Naturalists Article DOI: $10.1086 / 422263$.

This Article is brought to you for free and open access. It has been accepted for inclusion in Systems Science Faculty Publications and Presentations by an authorized administrator of PDXScholar. Please contact us if we can make this document more accessible: pdxscholar@pdx.edu. 


\title{
The Kin Composition of Social Groups: Trading Group Size for Degree of Altruism
}

\author{
Leticia Avilés, ${ }^{1,2, *}$ Jeffrey A. Fletcher, ${ }^{3, \dagger}$ and Asher D. Cutter ${ }^{2, \star}$
}

1. Department of Zoology, University of British Columbia, Vancouver, British Columbia V6T 1Z4, Canada;

2. Ecology and Evolutionary Biology, University of Arizona,

Tucson, Arizona 85721;

3. Systems Science Ph.D. Program, Portland State University, Portland, Oregon 97207

Submitted August 27, 2003; Accepted April 20, 2004;

Electronically published July 8, 2004

Online enhancements: appendix, color versions of figures.

ABSTRACT: Why some social systems form groups composed of kin, while others do not, has gone largely untreated in the literature. Using an individual-based simulation model, we explore the demographic consequences of making kinship a criterion in group formation. We find that systems where social groups consist of onegeneration breeding associations may face a serious trade-off between degree of altruism and group size that is largely mediated by their kin composition. On the one hand, restricting groups to close kin allows the evolution of highly altruistic behaviors but may limit group size to suboptimal levels, the more severely so the smaller the intrinsic fecundity of the species and the stricter the kin admission rule. Group size requirements, on the other hand, can be met by admitting nonkin into groups, but not without limiting the degree of altruism that can evolve. As a solution to this conundrum, we show that if helping roles within groups are assigned through a lottery rather than being genetically determined, maximum degrees of altruism can evolve in groups of nonrelatives of any size. Such a "lottery" mechanism may explain reproductive and helping patterns in organisms as varied as the cellular slime molds, pleometrotic ants, and Galapagos hawks.

Keywords: sociality, mutualism, cooperation, inclusive fitness, relatedness, lottery assignment of helping roles.

\footnotetext{
* Corresponding author; e-mail: laviles@zoology.ubc.ca.

${ }^{\dagger}$ E-mail: jeff@pdx.edu.

‡ E-mail: acutter@u.arizona.edu.
}

Am. Nat. 2004. Vol. 164, pp. 132-144. (c) 2004 by The University of Chicago. 0003-0147/2004/16402-40080\$15.00. All rights reserved.
Much of the study of social evolution in the last few decades has been concerned with the role of relatedness in the origin and maintenance of sociality. This concern originated in Hamilton's (1964) rule, which states that altruism will spread when $B R>C$ : the benefit to recipients, discounted by the relatedness of the actor to the recipients, exceeds the costs to the actor of an altruistic act. Facilitated by modern molecular techniques, researchers have measured intragroup relatedness in a great variety of social systems (for recent reviews, see Pamilo et al. 1997; Hughes 1998; Ross 2001; Clutton-Brock 2002), often discovering much lower levels than anticipated, even in highly altruistic systems (e.g., Rissing et al. 1989; Hughes et al. 1993; Kukuk and Sage 1994; Faaborg et al. 1995; Strassmann et al. 1995; Danforth et al. 1996; Goodisman and Ross 1997; Queller et al. 2000). These findings, along with the fact that even clonal organisms are for the most part nonsocial (Stern and Foster 1997), reinforce the need to place greater emphasis on the other two parameters of Hamilton's inequality-the costs and benefits of group living and cooperation. These parameters are largely a function of the ecological and demographic circumstances under which sociality evolves.

Because ecological and demographic factors are often diverse and complex (Rubenstein and Wrangham 1986; Slobodchikoff 1988; Janson 2000), it has been argued that a simple unified framework to explain sociality from an ecological perspective cannot be easily attained (e.g., Queller and Strassmann 1998). The problem can be simplified, however, by considering that the shape of the function relating average individual fitness to group size reflects the net effect of ecological interactions-cooperation, competition, predation, and resource acquisition - that affect the fitness of individuals living in groups. The form of this relationship can thus be used to make general predictions about the origin, size, and dynamics of social groups, as done in models of group size evolution (Giraldeau and Caraco 1993; Higashi and Yamamura 1993), group foraging (Clark and Mangel 1986; Giraldeau and Caraco 2000), cooperative breeding (Emlen 1984; Courchamp et al. 1999b; Kokko et al. 2001), reproductive skew 
Table 1: Vectors of acceptability indices based on kinship $\left(A\left[R_{j}\right]\right.$ in eq. [3]) for the four models of group formation

\begin{tabular}{lcccc}
\hline & \multicolumn{4}{c}{ Acceptability index $A\left(R_{j}\right)($ eq. [3] $)$} \\
\cline { 2 - 5 } Model & Sibs & First cousins & Second cousins & Nonkin \\
& $\left(R_{j}=1 / 2\right)$ & $\left(1 / 8 \leq R_{j}<1 / 2\right)$ & $\left(1 / 32 \leq R_{j}<1 / 8\right)$ & $\left(R_{j}<1 / 32\right)$ \\
\hline Nonkin & 1.0 & 1.0 & 1.0 & 1.0 \\
Kin preference & 1.0 & .7 & .4 & .1 \\
At least cousins & 1.0 & .7 & .4 & .0 \\
Sibs only & 1.0 & .0 & .0 & .0 \\
\hline
\end{tabular}

Note: Indices weight acceptability of prospective joiner to a group based on its average relatedness to existing group members. Equilibrium average within-group relatedness resulting from each of these models shown in figure 1 .

(Vehrencamp 1983; Reeve and Emlen 2000), and, more generally, group living and sociality (Avilés 1999, 2002; Krause and Ruxton 2002).

As shown in a previous article (Avilés 1999), relatively simple solutions for the expected size and dynamics of social groups and the conditions leading to group living and cooperation can be derived as a function of an intrinsic rate of growth, group carrying capacity, and cooperation parameters. This formulation uses the standard assumption that group living and cooperation cause certain components of fitness to increase as a function of group size (see models above; for empirical support of this assumption, see Raffa and Berryman 1987; Cash et al. 1993; Itô 1993; Wiklund and Andersson 1994; Avilés and Tufiño 1998; Clutton-Brock et al. 1999; Courchamp et al. 1999a). Building upon this framework, in a companion article (Avilés et al. 2002), we explored the evolution of onegeneration breeding associations among nonrelatives. Using an individual-based simulation model, we showed that among nonrelatives cooperative group living readily evolves when the relative fitness costs of cooperation within groups are small to moderate; larger group carrying capacities lead to the evolution of larger groups but lower cooperative tendencies; and the intrinsic rate of growth has no effect on equilibrium levels of cooperation, grouping tendencies, or the average group size but influences the dynamics - stable, periodic, or chaotic — of the groups and the global population.

Here, we examine the interaction between demography and kinship in social evolution by extending this model to a range of kinship structures. Our focus, however, is not on the effects of relatedness on social evolution per se, as this topic has already been the subject of extensive study (Hamilton 1964; Queller 1992; Frank 1998). Instead, we focus on the demographic consequences of making kinship a criterion in group formation. We argue that such demographic consequences, and their dependence on parameters such as the intrinsic fecundity of a species, cannot be ignored when trying to explain the kin composition of social groups.

\section{The Model}

As in Avilés et al. (2002), in this simulation model individuals come together in one-generation breeding associations as a function of their genetically coded "grouping" tendencies. Once within groups, individuals help one another as a function of their separately coded "cooperative" tendencies. Cooperation increases group productivity but, when interactions are altruistic, lowers the relative fitness of cooperators within groups. Following a social phase, offspring produced within the groups join a global pool from which they disperse to restart a new cycle of group formation. As generations of group formation proceed, grouping, cooperation, and the average group size evolve. We depart from Avilés et al. (2002), where only nonkin associations were considered, by systematically exploring a variety of rules that use kinship as a criterion in group admission (table 1). Other relatively minor departures from the Avilés et al. (2002) model are discussed in the appendix in the online edition of the American Naturalist.

\section{Per Capita Group Productivity and Relative Fitness within Groups}

We assume that the number of offspring produced per capita is maximized in groups of intermediate size, reflecting a balance between positive effects of cooperation and negative effects of crowding and competition within groups. Following Avilés (1999), this is modeled with the following function:

$$
f(n)=e^{r} e^{-c n} n^{\bar{\gamma}},
$$

where $n$ is the size of a group, $r$ is an intrinsic rate of growth parameter, $c$ is the inverse of a group carrying 
capacity parameter, and $\bar{\gamma}$, taken to range between 0 and 1 , represents the average cooperative tendencies of members of a group. Given these definitions, $e^{r}$ represents the reproductive output of members of a group in the absence of cooperative or competitive interactions, $e^{-c n}$ reflects the negative effects of crowding and competition given limited resources available to a group, and $n^{\bar{\gamma}}$ represents the synergistic effects of cooperation. The product of these three factors is a one-humped function when $\bar{\gamma}>0$ (Avilés 1999). In the simulations, $r$ and $c$ are fixed parameters of a run while $\bar{\gamma}$ evolves.

We allow for the possibility that cooperators suffer a relative fitness cost within their groups by multiplying equation (1) by the following relative fitness function,

$$
\text { relfitness }_{i}=a-\beta \gamma_{i}
$$

to calculate an individual's contribution to its group's offspring pool. In equation (2), $\gamma_{i}$ represents the cooperative tendencies of individual $i ; \beta$, the slope of the function, determines the extent to which cooperation carries a relative fitness cost; and $a$, the intercept of the function, is calculated so that the average cooperator within a group will have a relative fitness of 1.0 (i.e., $a=1+\beta \bar{\gamma}$, where $\bar{\gamma}$ is the average cooperative tendencies of members of a group). The parameter $\beta$ controls the extent to which interactions are mutualistic versus altruistic. When mutualistic $(\beta=0)$, cooperation carries no relative fitness costs and all group members benefit equally from communal activities. When altruistic $(\beta>0)$, individuals who help more have a lower proportional share of the group's offspring pool (for similar definitions of altruism, see Uyenoyama and Feldman 1980; Wilson 1990). In either case, groups with greater cooperative tendencies are more productive.

\section{Genetic and Breeding Systems}

Individuals are diploid, with grouping and cooperative tendencies each represented by 15 binary loci ( 0 or 1 as possible alleles) that translate additively to phenotypic values between 0.0 and 1.0 (proportion of 1's in the diploid complement). Haploid gametes are produced through processes mimicking meiosis and recombination. Mutation, at a rate of $10^{-2}$ per locus per generation, is implemented through an inversion/translocation mechanism to avoid the bias against the most common allele introduced from simply mutating randomly chosen sites to the opposite allele.

For simplicity, we model a single sex, with individuals primarily performing the female function but also being capable of contributing sperm. Because individuals choose mates at random from a large global population prior to group formation, selfing is avoided and the system is equivalent to a two-sex system in which males are only available to fertilize the eggs. The model is thus appropriate for organisms with outbred breeding systems (either where mating takes place prior to group formation or where males move between groups), but not for organisms characterized by inbred social groups such as the naked mole rats (Faulkes et al. 1997; Burland et al. 2002) or social spiders (Avilés 1997). To facilitate relatedness calculations, all offspring in a clutch are sired by the same father.

\section{Group Formation}

Groups form by accretion, with the probability that a new member joins a group being

$$
\operatorname{join}_{j}=g_{j} \times \bar{g} \times h(n) \times A\left(R_{j}\right)
$$

where $g_{j}$ represents the grouping tendency of the prospective joiner $j, \bar{g}$ is the average grouping tendencies of existing group members, and $h(n)$ and $A\left(R_{j}\right)$ weight admissibility into a group as a function of the number of existing group members and their average relatedness to the prospective joiner, respectively (see below; table 1).

We assume that groups are increasingly less likely to accept new members as they reach or exceed their optimum size, $n_{\text {opt }}$, and completely reject new joiners after reaching their stable size, $n^{*}$ (for a definition and calculation of these two quantities from eq. [1], see appendix). Accordingly, we set $h(n)=1$ when $n<n_{\text {opt }}, h(n)=$ $\left(n^{*}-n\right) /\left(n^{*}-n_{\text {opt }}\right)$ when $n_{\text {opt }} \leq n<n^{*}$, and $h(n)=0$ when $n \geq n^{*}$. Consistent with the empirical observation that groups in nature typically exceed their optimum size (see Giraldeau 1988), these functions imply that in the region of conflict over admission decisions between prospective joiners and the group-from the optimum to the stable group size (Giraldeau and Caraco 1993; Higashi and Yamamura 1993) — groups can only partially prevent admission of new members. Because $n_{\mathrm{opt}}$ and $n^{*}$ are a function of an evolving cooperation parameter (appendix), they also evolve in the simulations.

We explore four models of group formation leading to different degrees of relatedness within groups (table 1). These models-nonkin, kin preference, at least cousins, and sibs only-assume different acceptance probabilities for individuals of different degrees of relatedness to existing group members $\left(A\left[R_{j}\right]\right.$ in eq. [3]). We assess relatedness by keeping track of pedigree relationships up to the great grandmother generation, a task facilitated by the fact that all offspring in a clutch share the same father.

During the group formation phase, individuals leave the global pool one at a time in search of a group to join. In the sibs only, at least cousins, and kin preference models, 
individuals leave the global pool in order and visit most recently founded groups first. Because newly dispersed relatives occupy recently formed groups, this creates a linearly viscous population structure that maximizes encounters between relatives and, in the sibs only and at least cousins models, has the effect of producing groups that fission along family lines despite having been formed by accretion. We eliminate population viscosity in the nonkin model by having individuals depart the global pool in random order. In all models, potential immigrants continue to visit groups until accepted or until all groups have been visited. If no accepting groups are found, individuals initiate their own group. When all available sites are occupied (set at 200 in the current simulations), group formation stops, and individuals who failed to establish or join a group are removed from the simulations (note that this corresponds to the limited nesting sites model of global population control of Avilés et al. 2002).

\section{Lottery Model}

For the case of nonkin associations, we also explore a model in which helping roles within groups, and thus associated relative fitness costs (see above), are assigned randomly with respect to genotype. We accomplish this by first calculating expected levels of cooperation and relative fitnesses for all individuals in a group based on their genetically determined cooperative tendencies (as in the genetically based models described above) and then redistributing these values randomly among group members. With this model we explore the hypothesis that random assignment of helping roles within groups may explain the evolution of extreme altruism among nonrelatives (Gadagkar 1991; Wilson 2001).

\section{The Simulations and Analyses}

In all but the at least cousins model, we initiated the simulations with individuals who, except for new mutations, lacked grouping and cooperative tendencies. We ran each simulation for 4,500 generations and estimated equilibrium values by averaging over the last 1,000 generations. The evolving variables - cooperation, grouping tendencies, and the average group size-reached a stationary state in 1,000 to 3,000 generations. To account for greater fluctuations of the evolving variables, in the at least cousins model we initiated the runs with cooperation and grouping set at $\sim 0.3$ and calculated equilibrium values over the last 3,000 generations of 6,000-generation runs. For all four models of group formation, we systematically varied the relative fitness costs of cooperation $(\beta=0.0,0.2,0.4,0.6$, $0.8)$, intrinsic rate of growth $(r=0.5,1.0,1.5,2.0)$, and group carrying capacity $(1 / c=10,17,50)$ parameters and ran four replicates with different random number seeds for each combination of parameter values. As in Avilés et al. (2002), we evaluated the relative contribution of each of the parameters to the overall variance by calculating Type I sums of squares (terms introduced in the same order as in Avilés et al. 2002). We conducted separate analyses for each of the group formation models, with cooperation and grouping tendencies arcsine transformed and group size log transformed.

\section{Examples of Empirical Systems Resembled by the Models}

In Avilés et al. (2002), we list some 18 species or animal groups, from colonial birds to social bacteria, for which the nonkin model is appropriate. Examples to which the kin preference model applies include species of allodapine Exoneura bees (Schwarz et al. 1998) and of Polistes wasps (Strassmann 1996) in which females prefer relatives but will nest with unrelated females if kin are not available. Systems such as those of prairie voles (Getz et al. 1993), dwarf mongooses (Creel and Waser 1994), white-nosed coatis (Gompper et al. 1997), white-fronted bee-eaters (Emlen and Wrege 1988), and white-winged choughs (Heinsohn et al. 2000) are intermediate between the kin preference and the at least cousins or sib only models in that groups tend to be kin based, but nonrelatives are accepted or even sought out if kin are not available (e.g., Heinsohn 1991). Taxa known to form groups with kin of varying degrees of relatedness, as in the at least cousins model, include female lions (Packer et al. 1991), African wild dogs (Girman et al. 1997), and acorn woodpeckers (Haydock et al. 2001). More exclusive kin groups that approximate the sibs only model are found in some Hymenoptera (Pamilo et al. 1997; Peters et al. 1999), termites (Shellman-Reeve 1997), thrips (Chapman and Crespi 1998), wolves (Mech 1999), and some eusocial mole rats (Faulkes et al. 1997; Burland et al. 2002).

\section{Results}

\section{Intragroup Relatedness and the Intrinsic Rate of Growth}

In addition to the expected ranking in levels of intragroup relatedness across the four models of group admission (fig. 1), two interesting patterns emerged in the simulations: intragroup relatedness in the kin preference model was considerably lower than in the at least cousins model, despite an apparently minor difference in their kin admission rules, and intragroup relatedness in these two models was a function of the intrinsic rate of growth $(r$, in eq. [1]).

The low intragroup relatedness in the kin preference model reflects the fact that nonrelatives vastly outnumber 

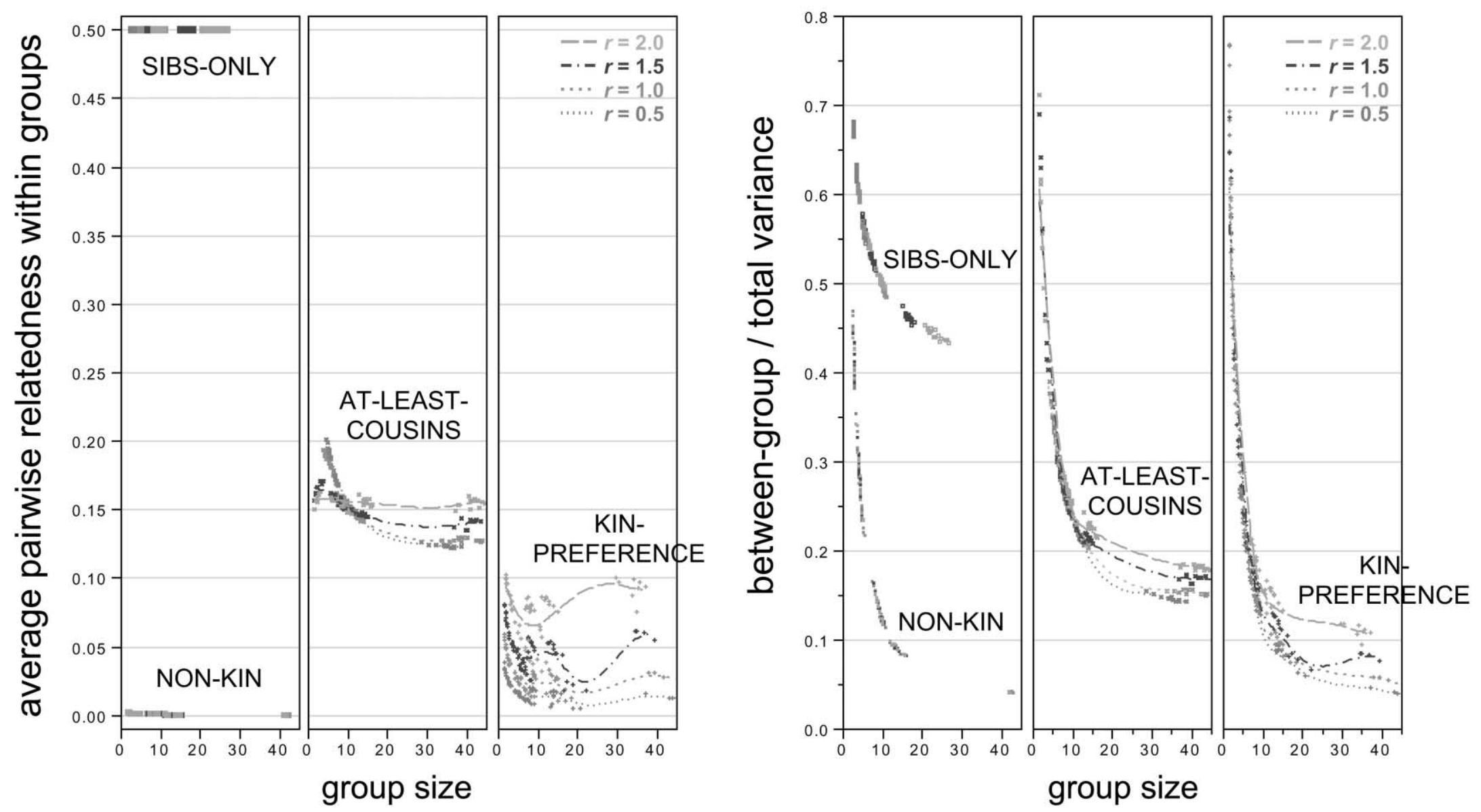

Figure 1: Average pairwise relatedness within groups (left) and between-group over total genetic variance (right) under each of the models of group formation. Lines are cubic spline fits $(\lambda=$ 100) for different values of the intrinsic rate of growth parameter ( $r$; eq. [1]). All levels of the group carrying capacity and relative fitness costs of cooperation included in the fits. Relatedness was calculated from pedigree relationships among group members, with the exclusion of self. The ratio of the variances, which depends on both genealogical relatedness and group size, was calculated on the phenotypic values of grouping and cooperation, averaged across the two traits. A color version of this figure is available in the online edition of the American Naturalist. 
relatives in populations. Thus, even though with this model nine out of 10 nonrelatives were rejected by the groups (table 1), so many attempted joining that intragroup relatedness was diluted nonetheless. This dilution effect was more dramatic the smaller the intrinsic rate of growth (fig. 1), reflecting the fact that the absolute number of relatives, and thus of opportunities a group has to incorporate them, decreases as a species' intrinsic fecundity decreases.

Relatedness was also lower for lower intrinsic rates of growth in the at least cousins model, but only when group size exceeded approximately 10 individuals. For smaller groups the opposite was true (fig. 1), reflecting the fact that in a one-generation pool of relatives the proportional representation of close versus more distant relatives decreases as the average family size increases. Thus, with an average family of two, the expected ratio of siblings to first cousins to second cousins is $2: 4: 8$; with an average family of four, the ratio is $4: 16: 64$, or, in general, $X^{1}: X^{2}: X^{3}$, where $X$ is the average family size. The bias against more distant relatives in our kin discrimination vector (table 1) was thus insufficient to counter this effect, and small groups quickly became saturated with the proportionally more abundant distant relatives. Differences in intragroup relatedness were reflected in different ratios of the between-group over total variances across models and intrinsic rates of growth (fig. 1).

\section{Evolution of Grouping and Group Size}

Restricting the groups to close kin, sibs in particular, severely limited the size of the groups formed, the more strongly the smaller the intrinsic rate of growth (fig. 2). In the sibs only model, for instance, groups were onequarter (for $r=1.0$; fig. 3) to one-fifth (for $r=0.5$; fig. 4) the size of the groups formed in the nonkin and kin preference models when interactions were mutualistic $(\beta=0)$ and the group carrying capacity was large $(1 / c=50)$. The discrepancy in emerging group size between the models disappeared, however, as greater relative fitness costs of cooperation prevented the evolution of large groups in the less kin-restricted models (figs. 2, 3). An associated effect concerned grouping tendencies, which evolved to increasingly greater levels the more restrictive the kin admission rule and, for models other than nonkin, the smaller the intrinsic rate of growth (fig. 2).

\section{Evolution of Cooperation}

When interactions were mutualistic $(\beta=0)$, cooperation evolved near its maximum value regardless of the kin admission rule (figs. 2, 3). As the cost of cooperation increased, however, equilibrium levels of cooperation de- clined precipitously when the groups contained nonrelatives, less steeply so when restricted to cousins, and imperceptibly so when restricted to sibs (figs. 2, 3). For all models, larger groups, greater grouping tendencies, but lower cooperative tendencies evolved as the group carrying capacity increased (fig. 3), as previously reported for the nonkin case in Avilés et al. (2002). While the intrinsic rate of growth had no effect on equilibrium levels of cooperation in the nonkin and sibs only models, cooperation was greater for larger $r$ in the kin preference model and lower for larger $r$ in the at least cousins model (fig. 2), paralleling the effects of this parameter on intragroup relatedness in these models (in the at least cousins model, for the case when groups were small; fig. 1).

\section{The Lottery Model for Nonkin Associations}

We found strong support for the hypothesis that randomly assigned helping roles within groups allow the evolution of highly altruistic behaviors $(\beta \gg 0)$ among nonrelatives. For all values of the relative fitness costs of cooperation, in the lottery-based nonkin model, cooperation evolved to levels almost as high as those in the sibs only model (fig. 4), with the difference that group size was not limited by the number of available relatives. As with the genetically based nonkin model, in the lottery model large group sizes evolved without need for high grouping tendencies (fig. 4 ), except that group sizes remained large even when costs of cooperation were high. Thus, random assignment of helping roles within groups allowed near maximal levels of cooperation in maximally sized groups, independently of how costly cooperation was (fig. 4).

\section{Relative Role of Parameters}

In the four genetically based models (table 1), there was a dramatic reversal in the roles played by different parameters in determining equilibrium levels of grouping tendencies and the average group size as the group admission rule became more strongly kin restricted. While costs of cooperation explained the largest fraction of the total variance in both sociality measures in the nonkin $60 \%$ and $62 \%$, respectively) and kin preference $(58 \%$ and $68 \%$, respectively) models, the intrinsic rate of growth became the primary determinant of grouping tendencies in the at least cousins model ( $81 \%$ of total variance) and of grouping tendencies and group size in the sibs only model $(75 \%$ and $49 \%$, respectively). Costs of cooperation continued to play the most important role in determining equilibrium levels of cooperation in all four genetically based models (58\% of explained variance in the sibs only model and $>80 \%$ of the explained variance in the remaining models) but had no effect on any of the sociality measures in the 


\section{Varying $r, 1 / c=17$}
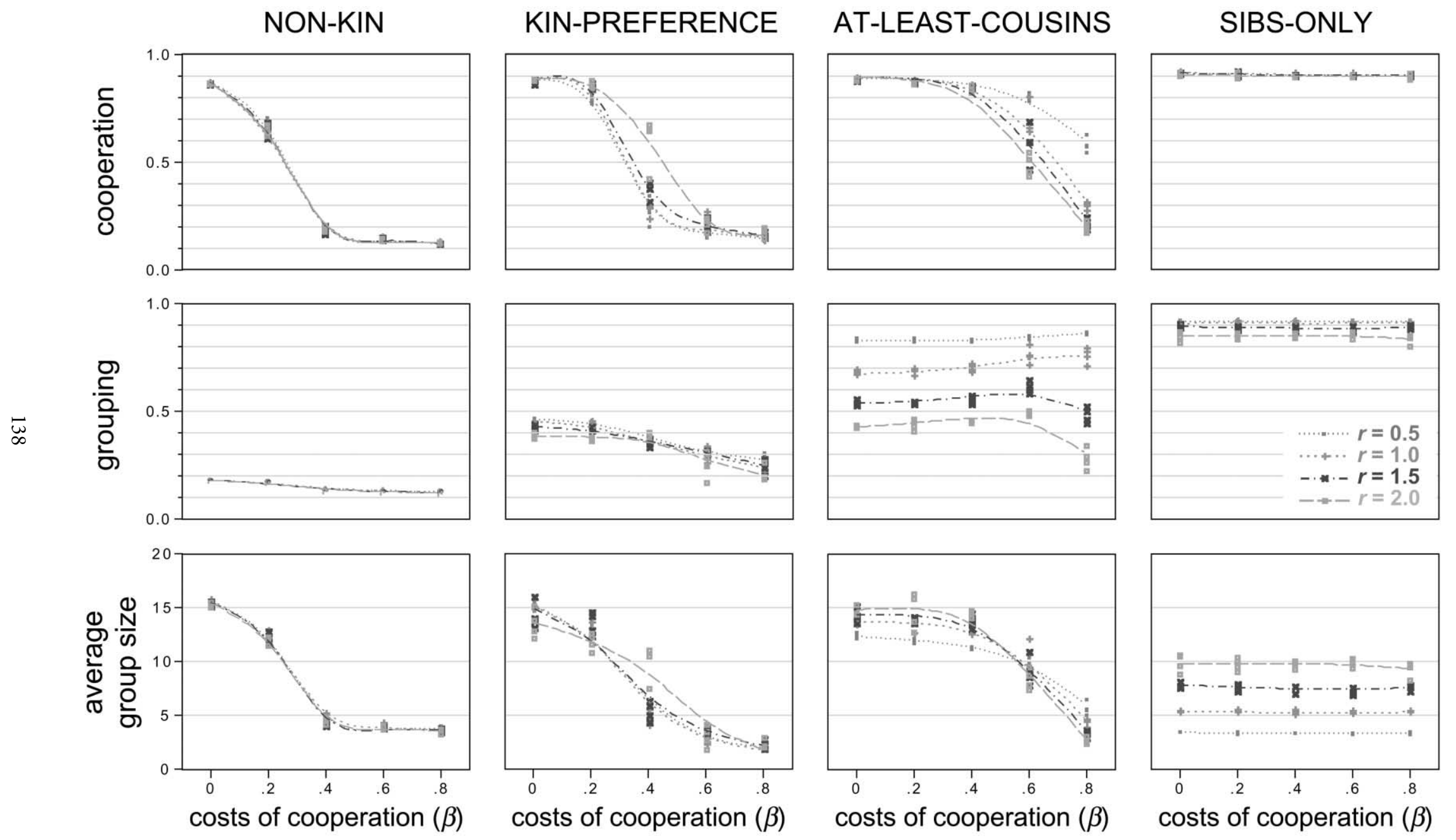

Figure 2: Equilibrium levels of cooperation, grouping tendencies, and the average group size as a function of the relative fitness costs of cooperation ( $\beta$; eq. [2]) and the intrinsic rate of growth ( $r$; eq. [1]). In all figures, $1 / c=17$. Lines shown are cubic spline fits of four replicates for each combination of parameter values (for the spline fits, $\lambda=0.01$ for all except cooperation and group size in the nonkin model and cooperation in the at least cousins model, where $\lambda=0.001$ ). A color version of this figure is available in the online edition of the American Naturalist. 


\section{Varying $1 / c ; r=1.0$}

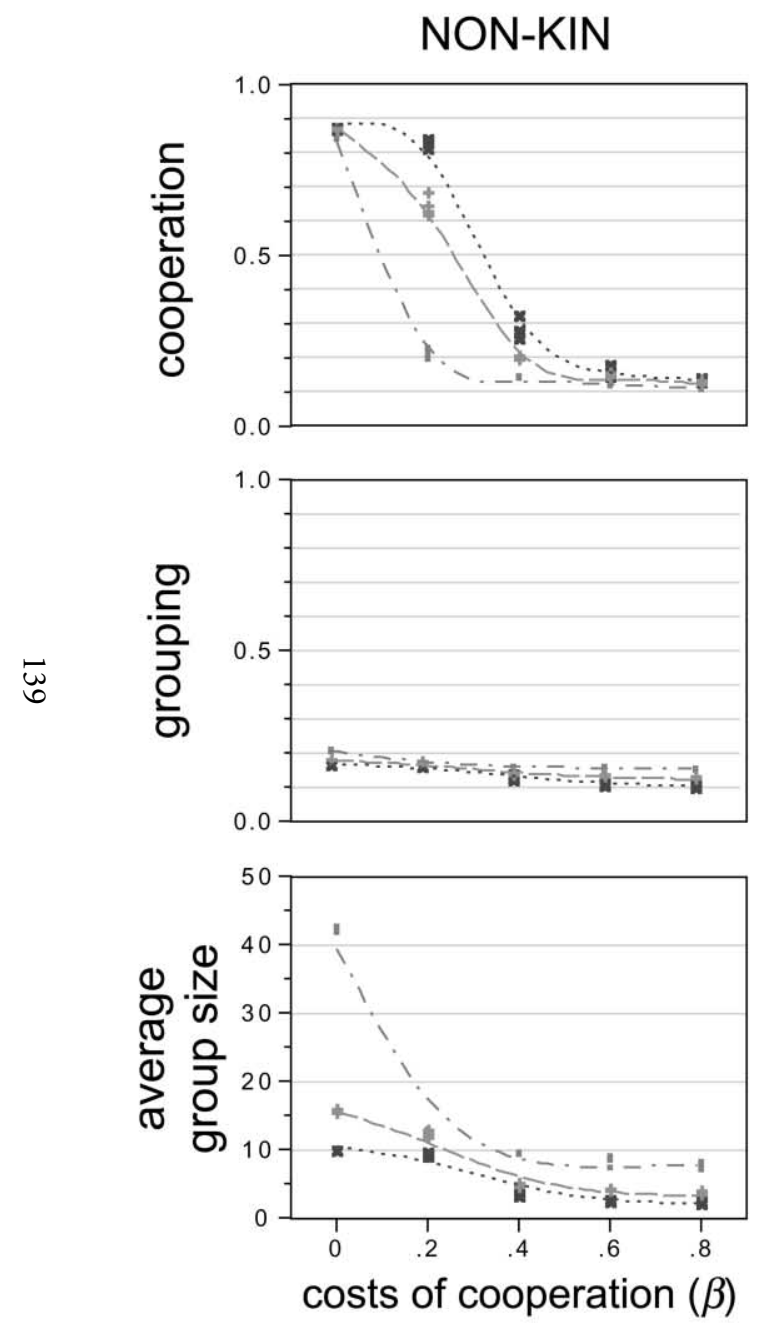

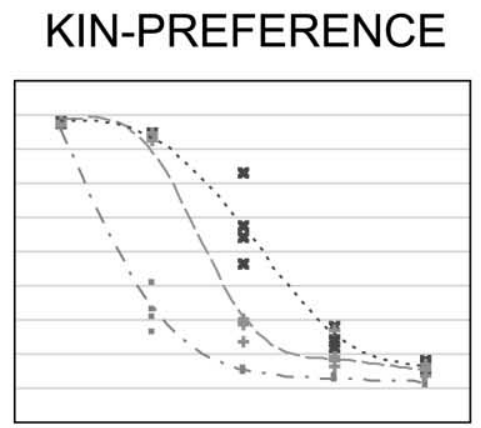
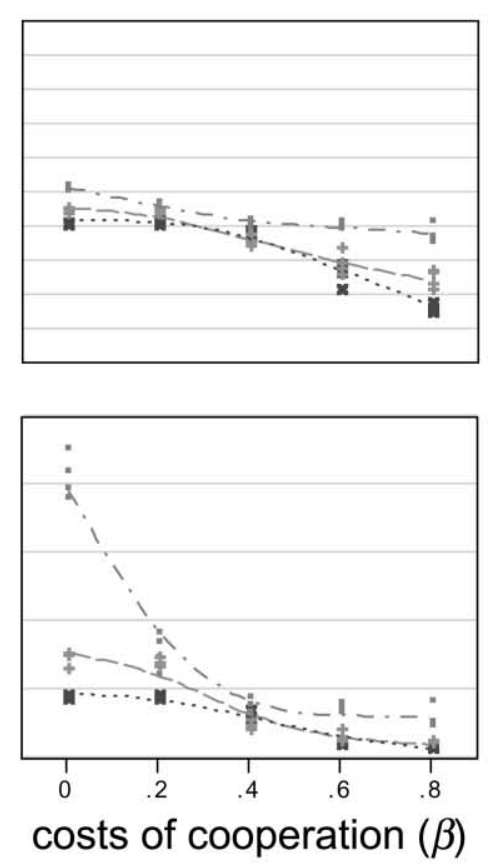
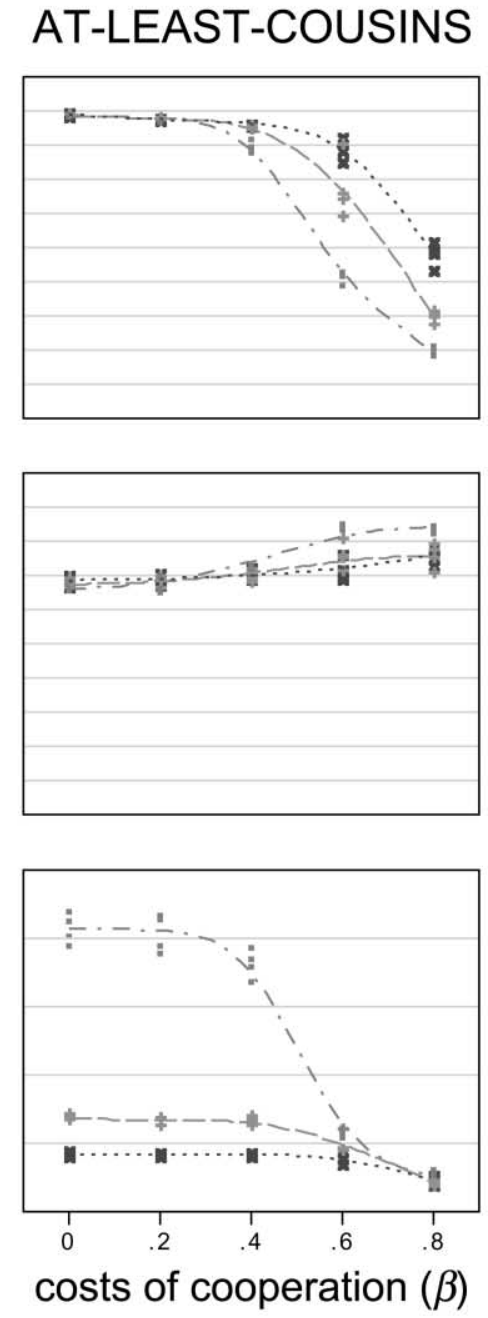
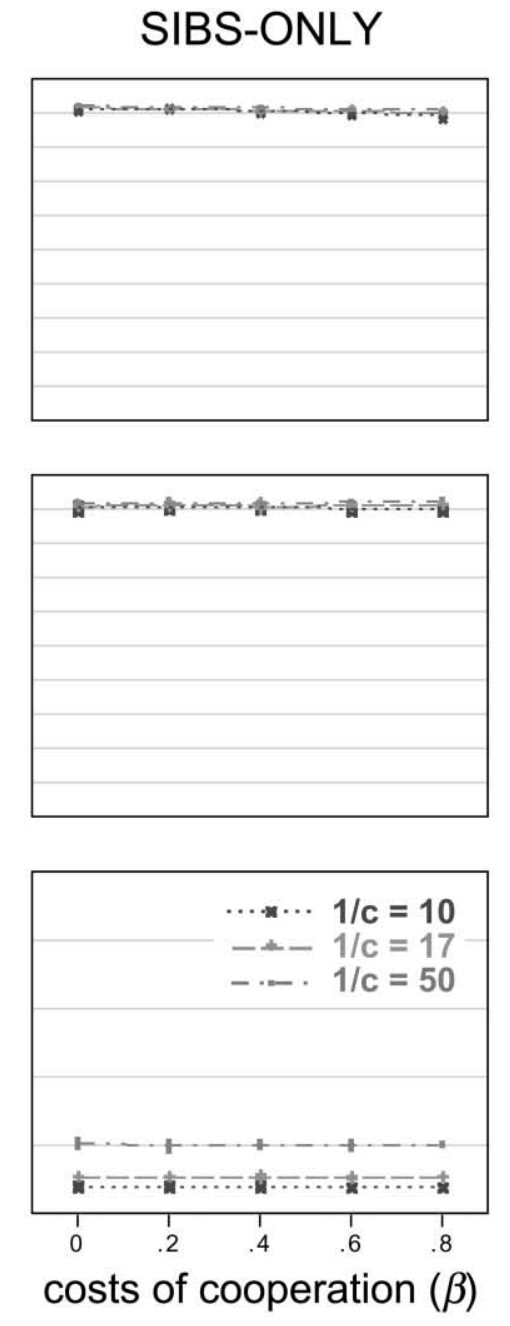

Figure 3: Equilibrium levels of cooperation, grouping tendencies, and the average group size as a function of the relative fitness costs of cooperation ( $\beta$; eq. [2]) and the group carrying capacity (1/c; eq. [1]). In all models, $r=1.0$. Lines shown are cubic spline fits of four replicates for each combination of parameter values $(\lambda=0.001$ for cooperation and $\lambda=0.01$ for grouping and group size, except for group size in the at least cousins model where $\lambda=0.001$ ). A color version of this figure is available in the online edition of the American Naturalist. 

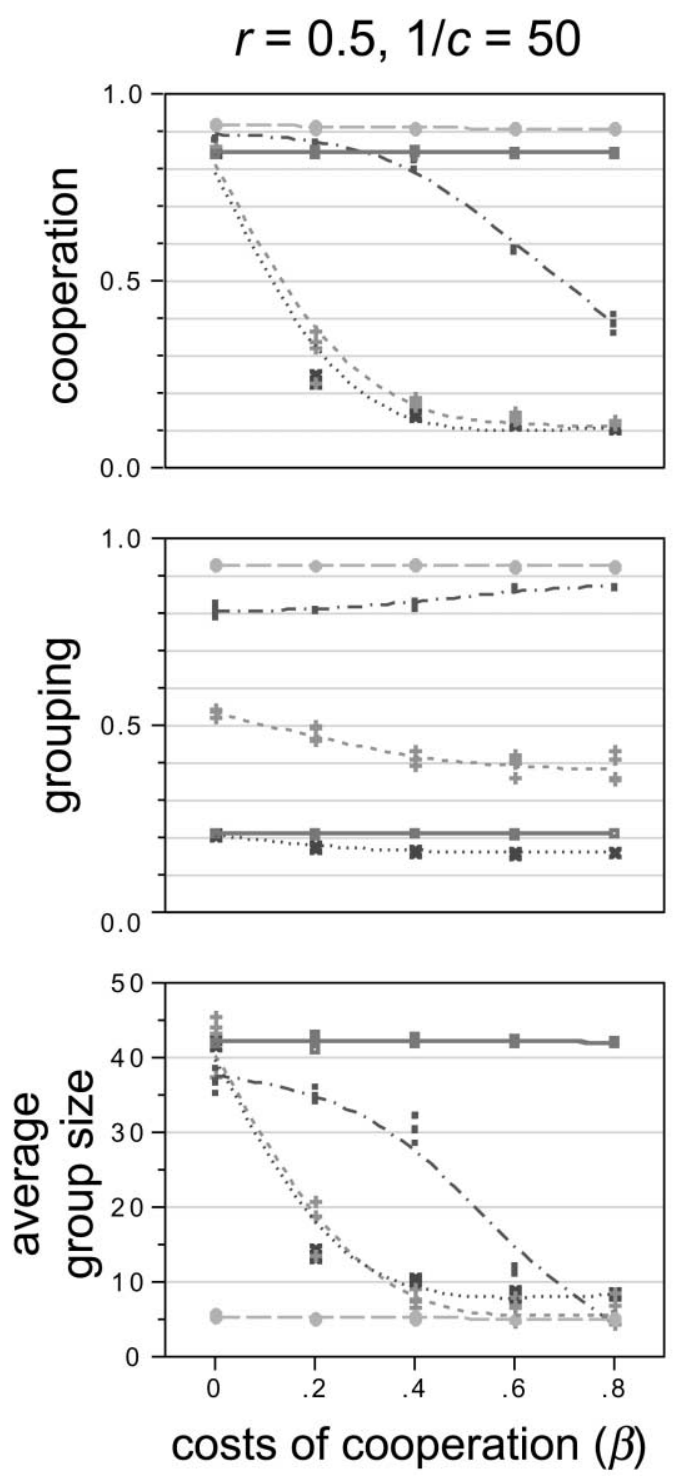

$\longrightarrow$ Non-Kin Lottery

$-\infty$ Sibs-Only

-... At-Least-Cousins

...-. Kin-Preference

.......... Non-Kin

Figure 4: Equilibrium levels of cooperation, grouping tendencies, and the average group size for the four models of group formation with genetic determination of helping roles (dashed lines) and for the nonkin lottery model with stochastic assignment of helping roles (solid line with square symbols). Lines shown are cubic spline fits $(\lambda=0.01)$ across four replicates for each combination of parameter values. A color version of this figure is available in the online edition of the American Naturalist.

lottery-based nonkin model $(P>.7$ for all three variables; fig. 4).

\section{Discussion}

One of the critical evolutionary decisions in the origin of a social system is whether or not to form groups with kin. Understanding the factors involved in this decision is key to understanding the diversity of kinship structures represented across social taxa (Pamilo et al. 1997; Hughes
1998; Ross 2001; Clutton-Brock 2002). Our results suggest that at least two factors must play a role in this decisiongroup size and degree of altruism, both as shaped by the particular ecology of a species.

Our results, as have others (e.g., Kokko et al. 2001), show that when interactions are mutualistic the kin composition of social groups has little effect on the level of cooperation that evolves. Thus, with mutualistic cooperation, groups should be free to incorporate as many nonrelatives as necessary to meet ecologically based group size 
requirements or accommodate constraints on group formation such as limited time to form groups or difficulty in identifying relatives.

On the other hand, our simulations also demonstrate an important and previously unappreciated trade-off between the well-known solution to the problem of altruism-restricting groups to close kin (Hamilton 1964; Queller 1992; Frank 1998)—and group size. While restricting the groups to close kin does facilitate the evolution of highly altruistic behaviors, it also severely limits group size, in particular in species with low reproductive output. Forming groups with close kin may thus not be an option when ecological demands require that groups be larger than the number of available relatives, the time available to form groups is limited, or relatives cannot be easily identified. The following are some examples:

The tree-killing bark beetles must assemble thousands to tens of thousands of individuals during the span of a few hours to a few days to accumulate the critical mass needed to overwhelm the defenses of live trees (Raffa and Berryman 1987).

In the Australian cooperative breeding choughs, a minimum of four individuals is needed to successfully raise one chick per year (Heinsohn 1992). Given the low reproductive rate of this species, and thus short supply of close relatives, the birds must kidnap and raise birds from other groups for help in brood care (Heinsohn 1991).

In cellular slime molds, admittance of members of multiple, not necessarily related clones, allows the formation of larger, faster migrating slugs (Foster et al. 2002).

Given limited time to find cofounding partners in the pleometrotic ants (Bernasconi and Strassmann 1999), individuals form groups with the more abundant and, thus, more commonly encountered nonrelatives.

In lions, larger male coalitions more successfully acquire and maintain access to breeding females. Thus, in the absence of close relatives, males form coalitions with nonrelatives (Packer et al. 1991).

Likewise, the polyandrous Galapagos hawks form coalitions of nonrelated males (Faaborg et al. 1995), presumably because close relatives are in short supply given the hawk's characteristically low fecundity.

These natural history observations and our results suggest that when a species' group size requirements exceed its average family size, social groups will be more likely to include nonkin. The mismatch may arise either because group size requirements are large (e.g., bark beetles, cellular slime molds) or because intrinsic fecundity is low (e.g., choughs, Galapagos hawks). In our simulations, had we allowed the group admission rule to evolve, we predict that admission requirements on the basis of kinship would be more lax at larger group carrying capacities and smaller intrinsic rates of growth. The resulting kin composition then becomes a factor influencing the extent to which highly altruistic behaviors can evolve.

Of course, the alternative to forming large groups from the outset is to build them up across generations. In such cases, large groups of closely related individuals can be formed regardless of the intrinsic fecundity of the species, as occurs in termites (Shellman-Reeve 1997), naked mole rats (Faulkes et al. 1997; Burland et al. 2002), many ant species, and in the development of multicellular organisms (Michod 1996). This strategy, however, may not be an option when the time to build up groups through internal recruitment is limited (as in most of the examples of nonkin systems listed in table 3 in Avilés et al. 2002) or when the small incipient groups (required to ensure close kinship) cannot be easily established in the absence of specialized protective structures such as claustral foundation (for the incipient groups) or egg shells and viviparity (for the incipient multicellular organisms).

So, what is a group to do when its size requirements must be met by admitting nonrelatives and costs of cooperation are high? A case in point are the cellular slime molds (Bonner 1982; Strassmann et al. 2000) where behaviors that involve giving up reproduction altogether have evolved in aggregations that contain hundreds to thousands of cells and, potentially, multiple clones (Foster et al. 2002). Our results show that a viscous population structure alone (data not shown) or preferred admission of kin (the kin preference model) are insufficient to allow the evolution of costly altruistic behaviors.

Our lottery model (fig. 4) demonstrates a potential solution to this dilemma-the stochastic rather than genetic determination of helping roles within groups. Such a possibility has been suggested for organisms as diverse as the cellular slime molds (Wilson 2001), polygynous wasps (Gadagkar 1991), and Galapagos hawks (Faaborg et al. 1995). In the cellular slime molds, for instance, the probability that a cell differentiates into a prespore or a prestalk may largely depend on its phase in the cell cycle at the time of aggregation (Gomer and Firtel 1987). Patterns of paternity in the polyandrous Galapagos hawks suggest that reproductive success is randomly distributed among males in a group, possibly a result of males alternating their copulations with the female in a schedule that the female might control (Faaborg et al. 1995). Coin-flipping mechanisms of a similar nature may be involved in the decision of which queen inherits the nest or stays home versus forages in pleometrotic ants (Rissing et al. 1989; Bernasconi and Strassmann 1999) or in communally nesting bees (Kukuk et al. 1998).

As with the rules of fair meiosis, which no doubt contribute to the mostly cooperative action of genes within individuals (Michod 1996), these lottery mechanisms would not be immune to cheating and would thus require 
enforcement through policing (Frank 1995) and punish $\rightarrow$ Bonner, J. T. 1982. Evolutionary strategies and development (Boyd and Richerson 1992). Nonetheless, by dis- mental constraints in the cellular slime molds. American connecting genes from behavior, these lottery rules would level the field in which individuals with different coop erative tendencies play. Naturalist 119:530-552.

In summary, we have shown that high levels of coopBoyd, R., and P. J. Richerson. 1992. Punishment allows eration can evolve in groups of any kin composition a: long as the costs of cooperation are low to nonexistent. With costly altruistic behaviors, restricting groups to close kin allows the evolution of high levels of cooperation, but it also imposes a limitation on the size of the groups formed, the more severely so the smaller the intrinsic fe $\rightarrow$ Cast cundity of the species and the stricter the kin admission rule. We point to a number of ecological circumstances under which this group size limitation is problematic and show that random rather than genetic assignment of help ing roles within groups allows the evolution of costly altruistic behaviors in groups of nonrelatives of any size.

\section{Acknowledgments}

This project was funded by the National Science Foundation DEB grant 9815938 to L.A. A.D.C. was supported by a National Defense Science and Engineering Graduate Fellowship. We thank M. Wade and three anonymous reviewers for comments on the model and manuscript.

\section{Literature Cited}

Allee, W. C. 1938. The social life of animals. Norton, New York.

Avilés, L. 1997. Causes and consequences of cooperation and permanent sociality in spiders. Pages 476-498 in $\mathrm{J}$ Choe and B. Crespi, eds. The evolution of social behaviour in insects and arachnids. Cambridge University Press, Cambridge.

. 1999. Cooperation and non-linear dynamics: an ecological perspective on the evolution of sociality. Evolutionary Ecology Research 1:459-477.

$\rightarrow-$. 2002. Solving the freeloaders paradox: genetic associations and frequency-dependent selection in the evolution of cooperation among nonrelatives. Proceed $\rightarrow$ ings of the National Academy of Sciences of the USA 99:14268-14273.

$\rightarrow$ Avilés, L., and P. Tufiño. 1998. Colony size and individual fitness in the social spider Anelosimus eximius. American Naturalist 152:403-418.

$\rightarrow$ Avilés, L., P. Abbot, and A. Cutter. 2002. Population ecology, nonlinear dynamics, and social evolution. I. Associations among nonrelatives. American Naturalis $\rightarrow$ 159:115-127.

$\rightarrow$ Bernasconi, G., and J. E. Strassmann. 1999. Cooperation among unrelated individuals: the ant foundress case $\rightarrow$ F Trends in Ecology \& Evolution 14:477-482. the evolution of cooperation (or anything else) in sizable groups. Ethology and Sociobiology 13:171-195.

Burland, T. M., N. C. Bennett, J. U. M. Jarvis, and C. G. Faulkes. 2002. Eusociality in African mole-rats: new insights from patterns of genetic relatedness in the Damaraland mole-rat (Cryptomys damarensis). Proceedings of the Royal Society of London B 269:1025-1030.

Cash, K., M. McKee, and F. Wrona. 1993. Short- and longterm consequences of grouping and group foraging in the free-living flatworm Dugesia tigrina. Journal of Animal Ecology 62:529-535.

Chapman, T. W., and B. Crespi. 1998. High relatedness and inbreeding in two species of haplodiploid eusocial thrips (Insecta: Thysanoptera) revealed by microsatellite analysis. Behavioral Ecology and Sociobiology 43:301306.

$\rightarrow$ Clark, C. W., and M. Mangel. 1986. The evolutionary advantages of group foraging. Theoretical Population Biology 30:45-75.

$\rightarrow$ Clutton-Brock, T. 2002. Breeding together: kin selection and mutualism in cooperative vertebrates. Science 296: 69-72.

$\rightarrow$ Clutton-Brock, T. H., D. Gaynor, G. H. McIlrath, A. D. C. Maccoll, R. Kansky, P. Chadwick, J. D. Skinner, et al. 1999. Predation, group size and mortality in a cooperative mongoose, Suricata suricatta. Journal of Animal Ecology 68:672-683.

Courchamp, F., T. Clutton-Brock, and B. Grenfell. 1999a. Inverse density dependence and the Allee effect. Trends in Ecology \& Evolution 14:405-410.

$\rightarrow$ Courchamp, F., B. Grenfell, and T. Clutton-Brock. $1999 b$. Population dynamics of obligate cooperators. Proceedings of the Royal Society of London B 266:557-563.

$\rightarrow$ Creel, S. R., and P. M. Waser. 1994. Inclusive fitness and reproductive strategies in dwarf mongooses. Behavioral Ecology 5:339-348.

$\rightarrow$ Danforth, B. N., J. L. Neff, and P. Barretto-Ko. 1996. Nestmate relatedness in a communal bee, Perdita texana (Hymenoptera: Andrenidae), based on DNA fingerprinting. Evolution 50:276-284.

Emlen, S. T. 1984. Cooperative breeding in birds and mammals. Pages 305-339 in J. R. Krebs and N. B. Davis, eds. Behavioural ecology: an evolutionary approach. Blackwell Scientific, Oxford.

Emlen, S. T., and P. H. Wrege. 1988. The role of kinship in helping decisions among white-fronted bee-eaters. Behavioral Ecology and Sociobiology 23:305-315.

Faaborg, J., P. G. Parker, L. Delay, T. De Vries, J. C. Bednarz, S. M. Paz, J. Naranjo, et al. 1995. Confirmation 
of cooperative polyandry in the Galapagos hawk (Buteogalapagoensis). Behavioral Ecology and Sociobiology 36: 83-90.

$\rightarrow$ Faulkes, C. G., D. H. Abbott, H. P. Obrien, L. Lau, M. R $\rightarrow$ Roy, R. K. Wayne, and M. W. Bruford. 1997. Microand macrogeographical genetic structure of colonies of naked mole-rats Heterocephalus glaber. Molecular Ecology 6:615-628.

$\rightarrow$ Foster, K. R., A. Fortunato, J. E. Strassmann, and D. C. Queller. 2002. The costs and benefits of being a chimera. Proceedings of the Royal Society of London B 269:2357- $\rightarrow$ 2362.

Frank, S. A. 1995. Mutual policing and repression of competition in the evolution of cooperative groups. Natur $\rightarrow \mathrm{Hi}$ 377:4294-4295.

- 1998. Foundations of social evolution. Princeton University Press, Princeton, N.J.

Gadagkar, R. 1991. Belonogaster, Mischocyttarus, Parapolybia and independent founding Ropalidia. Pages 149190 in K. G. Ross and R. W. Matthews, eds. Socia biology of wasps. Cornell University Press, Ithaca, N.Y.

$\rightarrow$ Getz, L. L., B. McGuire, T. Pizzuto, J. E. Hofmann, and B. Frase. 1993. Social organization of the prairie vole (Microtus-Ochrogaster). Journal of Mammalogy 74:4458.

$\rightarrow$ Giraldeau, L., and T. Caraco. 1993. Genetic relatednes: $\rightarrow$ and group size in an aggregation economy. Evolutionary Ecology 7:429-438.

- 2000. Social foraging theory. Princeton University Press, Princeton, N.J.

Giraldeau, L.-A. 1988. The stable group and the determinants of foraging group size. Pages 33-53 in C. N. Slobodchikoff, ed. The ecology of social behavior. Academic Press, San Diego, Calif.

$\rightarrow$ Girman, D. J., M. G. L. Mills, E. Geffen, and R. K. Wayne. 1997. A molecular genetic analysis of social structure, dispersal, and interpack relationships of the African wild dog (Lycaon pictus). Behavioral Ecology and Sociobiol. ogy 40:187-198.

$\rightarrow$ Gomer, R. H., and R. A. Firtel. 1987. Cell-autonomous determination of cell-type choice in Dictyostelium development by cell-cycle phase. Science 237:758-762.

$\rightarrow$ Gompper, M. E., J. L. Gittleman, and R. K. Wayne. 1997. Genetic relatedness, coalitions and social behaviour of white-nosed coatis, Nasua narica. Animal Behaviour $53 \rightarrow$ 781-797.

$\rightarrow$ Goodisman, M. A. D., and K. G. Ross. 1997. Relationship of queen number and queen relatedness in multiple $\rightarrow$ queen colonies of the fire ant Solenopsis invicta. Ecological Entomology 22:150-157.

$\rightarrow$ Hamilton, W. D. 1964. The genetical evolution of socia $\rightarrow$ Pam behaviour. Journal of Theoretical Biology 7:1-16.

$\rightarrow$ Haydock, J., W. D. Koenig, and M. T. Stanback. 2001.
Shared parentage and incest avoidance in the cooperatively breeding acorn woodpecker. Molecular Ecology 10:1515-1525.

Heinsohn, R., P. Dunn, S. Legge, and M. Double. 2000. Coalitions of relatives and reproductive skew in cooperatively breeding white-winged choughs. Proceedings of the Royal Society of London B 267:243-249.

$\rightarrow$ Heinsohn, R. G. 1991. Kidnapping and reciprocity in cooperatively breeding white-winged choughs. Animal Behaviour 41:1097-1100.

- 1992. Cooperative enhancement of reproductive success in white-winged choughs. Evolutionary Ecology 6:97-114.

Higashi, M., and N. Yamamura. 1993. What determines animal group size? insider-outsider conflict and its resolution. American Naturalist 142:553-563.

$\rightarrow$ Hughes, C. 1998. Integrating molecular techniques with field methods in studies of social behavior: a revolution results. Ecology 79:383-399.

Hughes, C. R., D. C. Queller, J. E. Strassmann, and S. K. Davis. 1993. Relatedness and altruism in Polistes wasps. Behavioral Ecology 4:128-137.

Itô, Y. 1993. Behavior and social evolution of wasps. Oxford series in ecology and evolution. Oxford University Press, Oxford.

Janson, C. H. 2000. Primate socio-ecology: the end of a golden age. Evolutionary Anthropology 9:73-86.

$\rightarrow$ Kokko, H., A. Johnstone, and T. H. Clutton-Brock. 2001. The evolution of cooperative breeding through group augmentation. Proceedings of the Royal Society of London B 268:187-196.

Krause, J., and G. D. Ruxton. 2002. Living in groups. Oxford University Press, Oxford.

$\rightarrow$ Kukuk, P. F., and G. K. Sage. 1994. Reproductivity and relatedness in a communal halictine bee Lasioglossum(Chilalictus)-Hemichalceum. Insectes Sociaux 41:443455.

Kukuk, P. F., S. A. Ward, and A. Jozwiak. 1998. Mutualistic benefits generate an unequal distribution of risky activities among unrelated group members. Naturwisenschaften 85:445-449.

Mech, L. D. 1999. Alpha status, dominance, and division of labor in wolf packs. Canadian Journal of Zoology, Revue Canadienne De Zoologie 77:1196-1203.

Michod, R. E. 1996. Cooperation and conflict in the evolution of individuality. II. Conflict mediation. Proceedings of the Royal Society of London B 263:813-822.

Packer, C., D. A. Gilbert, A. E. Pusey, and S. J. Obrien. 1991. A molecular genetic-analysis of kinship and cooperation in African lions. Nature 351:562-565.

Pamilo, P., P. Gertsch, P. Thoren, and P. Seppa. 1997. Molecular population genetics of social insects. Annual Review of Ecology and Systematics 28:1-25. 
$\rightarrow$ Peters, J. M., D. C. Queller, V. L. Imperatriz-Fonseca, D. W. Roubik, and J. E. Strassmann. 1999. Mate number, kin selection and social conflicts in stingless bees and honeybees. Proceedings of the Royal Society of London B 266:379-384.

$\rightarrow$ Queller, D. C. 1992. A general model for kin selection. Evolution 46:376-380.

$\rightarrow$ Queller, D. C., and J. E. Strassmann. 1998. Kin selection and social insects. BioScience 48:165-175.

$\rightarrow$ Queller, D. C., F. Zacchi, R. Cervo, S. Turillazzi, M. T. Henshaw, L. A. Santorelli, and J. E. Strassmann. 2000. Unrelated helpers in a social insect. Nature 405:784787.

$\rightarrow$ Raffa, K. F., and A. A. Berryman. 1987. Interacting selective pressures in conifer-bark beetle systems: a basis for reciprocal adaptations? American Naturalist 129:234-262.

$\rightarrow$ Reeve, K. R., and S. T. Emlen. 2000. Reproductive sken $\rightarrow$ and group size: an $\mathrm{N}$-person staying incentive model. Behavioral Ecology 11:640-647.

$\rightarrow$ Rissing, S. W., G. B. Pollock, M. R. Higgins, R. H. Hagen $\rightarrow$ and D. R. Smith. 1989. Foraging specialization without relatedness or dominance among co-founding ant queens. Nature 338:420-422.

$\rightarrow$ Ross, K. G. 2001. Molecular ecology of social behaviour: analyses of breeding systems and genetic structure. Molecular Ecology 10:265-284.

Rubenstein, D. I., and R. W. Wrangham. 1986. Ecological aspects of social evolution birds and mammals. Princeton University Press, Princeton, N.J.

$\rightarrow$ Schwarz, M. P., N. J. Bull, and K. Hogendoorn. 1998. Evolution of sociality in the allodapine bees: a review of sex allocation, ecology and evolution. Insectes Sociaux 45:349-368.

Shellman-Reeve, J. S. 1997. The spectrum or eusociality in termites. Pages 52-93 in J. Choe and B. Crespi, eds. The evolution of social behaviour in insects and arachnids. Cambridge University Press, Cambridge.
Slobodchikoff, C. N. 1988. The ecology of social behavior. Academic Press, San Diego, Calif.

Stern, D. L., and W. A. Foster. 1997. The evolution of sociality in aphids: a clone's-eye view. Pages 150-165 in J. Choe and B. Crespi, eds. The evolution of social behaviour in insects and arachnids. Cambridge University Press, Cambridge.

Strassmann, J. E. 1996. Selective altruism towards closer over more distant relatives in colonies of the primitively eusocial wasp, Polistes. Pages 190-201 in S. Turillazzi and M. J. West-Eberhard, eds. Natural history and evolution of paper-wasps. Oxford University Press, Oxford.

$\rightarrow$ Strassmann, J. E., D. C. Queller, and C. R. Solis. 1995. Genetic relatedness and population-structure in the social wasp, Mischocyttarus-Mexicanus (Hymenoptera, Vespidae). Insectes Sociaux 42:379-383.

Strassmann, J. E., Y. Zhu, and D. C. Queller. 2000. Altruism and social cheating in the social amoeba Dictyostelium discoideum. Nature 408:965-967.

Uyenoyama, M., and M. W. Feldman. 1980. Theories of kin and group selection: a population genetics perspective. Theoretical Population Biology 17:380-414.

$\rightarrow$ Vehrencamp, S. L. 1983. A model for the evolution of despotic versus egalitarian societies. Animal Behavior 31:667-682.

$\rightarrow$ Wiklund, C. G., and M. Andersson. 1994. Natural selection of colony size in a passerine bird. Journal of Animal Ecology 63:765-774.

$\rightarrow$ Wilson, D. S. 1990. Weak altruism, strong group selection. Oikos 59:135-140.

- 2001. Cooperation and altruism. Pages 222-231 in C. W. Fox, D. A. Roff, and D. J. Fairbairn, eds. Evolutionary ecology: concepts and case studies. Oxford University Press, Oxford. 